\title{
Effect of roasting on comparative physical characteristics of linseed kernels
}

\author{
Sugandha Sharma ${ }^{1}$, Harsh P. Sharma ${ }^{2}$ and K. Prasad ${ }^{* 1}$ \\ ${ }^{1}$ Department of Food Engineering and Technology, SLIET, Longowal - 148106 \\ ${ }^{2}$ Deptt. of Food Processing Technology, College of Food Processing Technology \& Bio Energy,
}

AAU, Anand - 388110

(*Email: dr_k_prasad@rediffmail.com)

\begin{abstract}
The changes in physical and optical properties of linseed kernels on roasting were assessed. Physical properties play vital role in quality characterization, selection and in design of handle, transport and process equipment. Twelve popular linseed varieties LC2023, LC-2063, LC-54, Padmini, Sheela, Shekhar, Sweta, Chambal, Suyog, Himani, Neelam, Surbhi were selected for the present study. Physical properties like as geometrical, gravimetrical, frictional and optical properties of roasted linseeds were compared with raw linseeds. Results indicated that roasting decreased the seed length, width and aspect ratio from 4.89 to $4.69 \mathrm{~mm}, 2.41$ to $2.28 \mathrm{~mm}$ and 49.34 to 48.53 , respectively while thickness, geometric mean diameter and surface area increased linearly from 0.86 to $1.53 \mathrm{~mm}, 3.42$ to $5.54 \mathrm{~mm}, 38.78$ to $101.84 \mathrm{~mm}^{2}$, respectively. Thousand seed weight, bulk density, true density and porosity decreased after roasting from 7.55 to $7.38 \mathrm{~g}, 671.83$ to $631.13 \mathrm{~kg} / \mathrm{m}^{3}, 1093.26$ to 841.28 and 38.40 to $25.04 \%$, respectively. The static coefficient of friction found minor differences and varied in the range of 0.35 to $0.37,0.33$ to $0.36,0.38$ to 0.30 , and 0.33 to 0.32 for ply perpendicular, ply parallel, glass and galvanized iron surfaces, respectively. The angle of repose decreased linearly from $20.01^{\circ}$ to $17.52^{\circ}$ after roasting of linseed. Colour also changed after roasting as per the result of optical properties.
\end{abstract}

Keywords: Linseed, physical, frictional, optical, gravimetric property.

Linseed (Linum usitatissiumum) belongs to family Linaceae andalso known as flaxseed, alsi and chickna in India. It is one of the most important oilseed crops in the world (Coskuner and Karababa, 2007). Linseed plant is supposed to be the native of India and the eastern Mediterranean. It is grown throughout the world including Canada, China, United States and Ethiopia (FAOSTAT, 2013). India contributes almost 20 percent of the total world production of linseed and also governs the linseed production among Asian countries. Madhya Pradesh, Uttar Pradesh, Maharashtra, Bihar, Rajasthan, West Bengal, Karnataka, Orissa, Andhra Pradesh, and Himachal Pradesh are the major states growing this crop with a total area under cultivation is about 2.5 million hectares. India governs the linseed production of Asian countries and contributes almost 20 percent of the total world production (Sharma and Prasad, 2013).

Linseed is one of the leading vegetable sources of essential fatty acid. As alpha-linolenic acid (ALA), the omega-3 fatty acid, it is present in linseed oil to an extent of $45-50 \%$. It contains $73 \%$ polyunsaturated fatty acids, $18 \%$ monounsaturated fatty acids and low saturated fatty acids below 9\% (Thompson et al., 1995). Regular intake of small portions of linseeds in the diet helps to lower total an low density lipoprotein a bad cholesterol. It is found that consumption of linseed increases high density lipoprotein a good cholesterol in the blood (Oomah, 2001). Thus reduces the occurrence of high blood pressure and also found useful in diabetes, asthma and arthritis. Cynogenic glucoside (linustatin, neolinustatin, linamarin and lotaustralin) was also found to be reported in linseed to an extent of $0.1 \%$. Some report says that cyanide may also be present in the linseed but it is to be worth to mention that an adult can detoxify 30-100 mg of cyanide per day. Although presence anti-nutritional compound are reflected but the bodily detoxifying mechanism and the associated merits makes this item a unique functional biomaterial to be used in the preparation of foods. Further, roasting converts linseed safe with the rich source of monounsaturated and omega-3 essential fatty acids (Prasad, 2003). Linseed oil is probably best known for its functional properties in 
the production of paints and floor covering (Singh et al., 2011).

The physical properties of linseeds and like those of other grains and seeds are essential for the design of equipments, especially for handling, processing and storing the grains. To the best of our knowledge, there is no detailed study regarding the comparison of physical properties of raw and roasted flaxseed. The objective of this study was to investigate some physical properties of linseeds (Raw and Roasted) namely size, volume, shape, surface area, thousand kernels weight, true density, bulk density, porosity, coefficient of friction on the different surface of different materials and angle of repose and optical properties.

\section{Material and method}

Raw Material: Twelve major varieties of linseed grown in India, viz. LC-2023, LC-2063, LC-54, Padmini, Sheela, Shekhar, Sweta, Chambal, Suyog, Himani, Neelam, Surbhi were procured from CSAUA\&T, Kanpur and PAU, Ludhiana. Kernels of all varieties were subjected to air classifier to remove the dirt, dist, chaffs, lighter particles as well as damaged kernels. All varieties kernels were roasted in a similar temperature time combinations. Linseed kernels were roasted in a metallic roasting pan for 510 seconds. The roasted kernels were then cool to room temperature. The physical and optical properties were determined (Prasad et al., 2010; Sharma and Prasad, 2013).

Dimensional Properties: The particle size analysis of cleaned raw linseed kernels and roasted linseed kernels was determined through the developed image analysis technique (Prasad et al., 2012).The geometric mean diameter $(\mathrm{Dg})$, surface area $(\mathrm{S} \alpha)$ and aspect ratio $(R a)$ was calculated as described elsewhere (Prasad et al., 2010; Singh and Prasad, 2013).

Gravimetric properties: Thousand seed weight was determined using electronic balance. The bulk density is the ratio of the mass sample of the seeds to its total volume (Gupta and Das, 2000). The true density is defined as the ratio of mass of seed to the solid volume occupied. The seed volume and its true density was determined using liquid displacement technique. Toluene was used in spite of water so as to prevent the absorption during measurement and also to get the benefit of low surface tension of selected solvent. The porosity $(\varepsilon)$ of bulk seed was computed from the values of true density $(\rho t)$ and bulk density ( $\rho b)$ (Konak et al, 2002).
Frictional properties: The coefficient of static friction was determined with respect to four surfaces: plywood parallel, plywood perpendicular, stainless steel, glass. These are common materials used for transportation, storage and handling operations of grains, pulses and seeds construction of storage and drying bins. To determine the angle of repose, a cylinder (50 $\mathrm{mm}$ diameter and $60 \mathrm{~mm}$ height) was kept vertically on a horizontal galvanized metal floor and filled with the sample. The height of heap above the floor and the diameter of the heap at its base were measured and the angle of repose $(\theta)$ was determined. The angle of repose was calculated from the height and diameter of the naturally formed heap of the seeds on a circular plate (Jha, 1999).

Optical properties: Colour Parameters to measure colour, L, a and b values of the flaxseed were determined by color spectrophotometer (Prasad et al., 2010, Singh and Prasad, 2013).

Where,

$\mathrm{L}=$ degree of lightness to darkness

$\mathrm{a}=$ degree of redness to greenness

$\mathrm{b}=$ degree of yellowness to blueness

\section{Results and Discussion}

Dimensional Properties: The length, width and thickness of the raw linseed varieties varied from 4.35 (var. Surbhi) to $5.58 \mathrm{~mm}$ (var. Neelam), 2.10 (var. Surbhi) to $2.86 \mathrm{~mm}$ (var. Neelam) and 0.74 (var. LC-2063) to $1.03 \mathrm{~mm}$ (var. Neelam ), respectively and length, breadth and thickness of the roasted linseed varieties varied from 4.09 (var. Surbhi) to 5.36 (var. Neelam), 2.02 (var. LC-54) to 2.77 (var. Neelam ), 1.36 (var. LC-54) to 1.80 (var. Neelam ), respectively (Table 1). It is found that the length and width of linseed decreases on roasting whereas thickness increases. Geometric mean diameter (GMD), surface area and aspect ratio of raw linseed ranged from 2.33 (var. Surbhi) to $5.45 \mathrm{~mm}$ (var. Neelam), 17.08 to $93.43 \mathrm{~mm}$ and 46.36 (var. LC-54) to 51.85 (var. Chambal), respectively and roasted linseed 4.12 (var. Surbhi) to 8.91 (var. Neelam), 53.27 (var. Surbhi) to 249.36 (var. Neelam) and 44.64 (var. LC-54) to 52.18 (var. Surbhi), respectively. It is further reflected that increase in GMD and surface area whereas the aspect ratio decreases on roasting.

Gravimetric Properties: The true density of raw linseed varieties was in the range of $1,006.00$ (var. Neelam) to $1,198.33$ (var. Chambal) $\mathrm{kg} / \mathrm{m}^{3}$ and roasted linseed 798.99 (var.LC-2023) to 894.33 (var. Shekhar) $\mathrm{kg} / \mathrm{m}^{3}$ (Table 2). Bulk density of raw linseed was found in the range of 571.31 (var. 
Table 1: Dimensional properties of raw and roasted linseed

\begin{tabular}{|c|c|c|c|c|c|c|c|c|c|c|c|c|}
\hline \multirow{2}{*}{ Variety } & \multicolumn{2}{|c|}{ Length(mm) } & \multicolumn{2}{|c|}{ Width(mm) } & \multicolumn{2}{|c|}{ Thickness(mm) } & \multicolumn{2}{|c|}{ Aspect ratio } & \multicolumn{2}{|c|}{ Surface $\operatorname{area}\left(\mathrm{mm}^{2}\right)$} & \multicolumn{2}{|c|}{ GMD (mm) } \\
\hline & Raw & Roasted & Raw & Roasted & Raw & Roasted & Raw & Roasted & Raw & Roasted & Raw & Roasted \\
\hline LC-2023 & 4.61 & 4.50 & 2.32 & 2.22 & 0.81 & 1.48 & 50.47 & 49.25 & 25.95 & 76.69 & 2.87 & 4.94 \\
\hline LC-2063 & 4.68 & 4.50 & 2.30 & 2.19 & 0.74 & 1.39 & 49.14 & 48.58 & 22.52 & 65.63 & 2.66 & 4.56 \\
\hline LC-54 & 4.77 & 4.52 & 2.21 & 2.02 & 0.88 & 1.36 & 46.36 & 46.64 & 30.50 & 54.67 & 3.10 & 4.15 \\
\hline Padmini & 4.93 & 4.91 & 2.49 & 2.38 & 0.86 & 1.54 & 50.50 & 48.33 & 39.25 & 113.42 & 3.53 & 5.99 \\
\hline Sheela & 4.96 & 4.76 & 2.36 & 2.23 & 0.84 & 1.52 & 47.66 & 46.82 & 33.98 & 90.62 & 3.29 & 5.37 \\
\hline Shekhar & 4.96 & 4.69 & 2.51 & 2.44 & 0.94 & 1.63 & 50.66 & 52.02 & 48.17 & 121.99 & 3.91 & 6.20 \\
\hline Sweta & 4.94 & 4.79 & 2.51 & 2.38 & 0.84 & 1.59 & 50.82 & 49.68 & 38.06 & 114.78 & 3.48 & 6.03 \\
\hline Chambal & 4.89 & 4.99 & 2.53 & 2.29 & 0.76 & 1.52 & 51.85 & 45.84 & 31.64 & 105.99 & 3.14 & 5.79 \\
\hline Suyog & 5.37 & 4.87 & 2.49 & 2.27 & 0.93 & 1.59 & 46.43 & 46.49 & 54.44 & 109.95 & 4.16 & 5.88 \\
\hline Himani & 4.65 & 4.35 & 2.27 & 2.04 & 0.88 & 1.55 & 48.84 & 46.94 & 30.31 & 65.69 & 3.10 & 4.57 \\
\hline Neelam & 5.58 & 5.36 & 2.86 & 2.77 & 1.03 & 1.80 & 51.17 & 51.66 & 93.43 & 249.33 & 5.45 & 8.91 \\
\hline Surbhi & 4.35 & 4.09 & 2.10 & 2.13 & 0.77 & 1.42 & 48.22 & 52.18 & 17.08 & 53.27 & 2.33 & 4.11 \\
\hline
\end{tabular}


Table 2: Gravimetrical properties of raw and roasted linseed

\begin{tabular}{lcccccccc}
\hline \multirow{2}{*}{ Variety } & \multicolumn{2}{c}{ Bulk density $\left(\mathbf{k g} / \mathbf{m}^{\mathbf{3}}\right)$} & \multicolumn{2}{c}{ True density $\left(\mathbf{k g} / \mathbf{m}^{\mathbf{3}}\right)$} & \multicolumn{2}{c}{ Porosity $(\%)$} & \multicolumn{2}{c}{ 1000 Seed wt. $(\mathbf{g})$} \\
\cline { 2 - 9 } & Raw & Roasted & Raw & Roasted & Raw & Roasted & Raw & Roasted \\
\hline LC-2023 & 711.989 & 555.132 & 1056.111 & 798.988 & 32.581 & 30.499 & 6.097 & 5.530 \\
LC-2063 & 670.533 & 641.603 & 1103.333 & 890.556 & 39.208 & 27.935 & 6.523 & 6.370 \\
LC-54 & 738.303 & 710.127 & 1111.667 & 845.893 & 33.565 & 16.017 & 6.903 & 6.267 \\
Padmini & 660.000 & 659.649 & 1098.333 & 888.889 & 39.905 & 25.735 & 8.020 & 7.290 \\
Sheela & 571.308 & 459.135 & 1099.167 & 815.972 & 47.993 & 43.731 & 7.503 & 8.910 \\
Shekhar & 761.590 & 654.970 & 1077.500 & 894.333 & 29.289 & 26.717 & 8.557 & 8.837 \\
Sweta & 652.909 & 691.753 & 1054.000 & 804.702 & 38.041 & 14.036 & 8.023 & 8.397 \\
Chambal & 680.533 & 559.845 & 1198.333 & 817.202 & 43.195 & 31.432 & 7.080 & 7.077 \\
Suyog & 676.933 & 629.444 & 1091.333 & 804.345 & 37.948 & 21.706 & 8.997 & 8.090 \\
Himani & 654.297 & 688.557 & 1067.500 & 845.417 & 38.704 & 18.509 & 6.503 & 5.987 \\
Neelam & 659.614 & 801.318 & 1006.000 & 872.667 & 34.394 & 8.153 & 10.967 & 10.470 \\
Surbhi & 624.005 & 522.043 & 1155.833 & 816.429 & 46.010 & 36.032 & 5.420 & 5.367 \\
\hline
\end{tabular}

Table 3:Frictional properties of raw and roasted linseed

\begin{tabular}{|c|c|c|c|c|c|c|c|c|c|c|}
\hline \multirow[t]{3}{*}{ Variety } & \multicolumn{8}{|c|}{ Coefficient of Friction } & \multirow{2}{*}{\multicolumn{2}{|c|}{ Angle of repose $\left(^{0}\right)$}} \\
\hline & \multicolumn{2}{|c|}{ Ply perpendicular } & \multicolumn{2}{|c|}{ Ply parallel } & \multicolumn{2}{|c|}{ Steel } & \multicolumn{2}{|c|}{ Glass } & & \\
\hline & Raw & Roasted & Raw & Roasted & Raw & Roasted & Raw & Roasted & Raw & Roasted \\
\hline LC-2023 & 0.34 & 0.35 & 0.32 & 0.35 & 0.32 & 0.33 & 0.38 & 0.34 & 18.39 & 17.80 \\
\hline LC-2063 & 0.32 & 0.34 & 0.30 & 0.34 & 0.34 & 0.34 & 0.35 & 0.30 & 21.75 & 17.85 \\
\hline LC-54 & 0.33 & 0.35 & 0.30 & 0.34 & 0.30 & 0.30 & 0.37 & 0.28 & 24.45 & 13.12 \\
\hline Padmini & 0.34 & 0.36 & 0.32 & 0.33 & 0.34 & 0.33 & 0.36 & 0.30 & 18.41 & 18.99 \\
\hline Sheela & 0.35 & 0.43 & 0.37 & 0.36 & 0.37 & 0.32 & 0.40 & 0.29 & 22.31 & 19.56 \\
\hline Shekhar & 0.39 & 0.36 & 0.35 & 0.35 & 0.35 & 0.34 & 0.41 & 0.27 & 20.60 & 17.27 \\
\hline Shweta & 0.34 & 0.41 & 0.33 & 0.39 & 0.33 & 0.32 & 0.43 & 0.31 & 19.56 & 20.12 \\
\hline Chambal & 0.34 & 0.37 & 0.33 & 0.34 & 0.33 & 0.32 & 0.41 & 0.28 & 20.09 & 15.48 \\
\hline Suyog & 0.34 & 0.38 & 0.31 & 0.38 & 0.34 & 0.32 & 0.41 & 0.31 & 18.41 & 15.48 \\
\hline Himani & 0.34 & 0.38 & 0.33 & 0.34 & 0.32 & 0.31 & 0.39 & 0.29 & 21.73 & 16.68 \\
\hline Neelam & 0.34 & 0.39 & 0.32 & 0.32 & 0.33 & 0.31 & 0.34 & 0.30 & 24.40 & 20.68 \\
\hline Surbhi & 0.37 & 0.35 & 0.33 & 0.46 & 0.32 & 0.31 & 0.34 & 0.29 & 10.06 & 17.27 \\
\hline
\end{tabular}


Table 4:Optical properties of raw and roasted linseed

\begin{tabular}{lcccccccc}
\hline \multirow{2}{*}{ Variety } & \multicolumn{2}{c}{ L } & \multicolumn{2}{c}{ a } & \multicolumn{2}{c}{ b } & \multicolumn{2}{c}{ Colour difference } \\
\cline { 2 - 9 } & Raw & Roasted & Raw & Roasted & Raw & Roasted & Raw & Roasted \\
\hline LC-2023 & 49.367 & 45.670 & 9.738 & 6.337 & 11.990 & 8.116 & 51.727 & 46.819 \\
LC-2063 & 49.298 & 44.253 & 6.717 & 5.479 & 11.707 & 7.028 & 51.285 & 45.142 \\
LC-54 & 49.531 & 45.594 & 10.013 & 6.516 & 12.261 & 8.393 & 52.001 & 46.816 \\
Padmini & 48.854 & 46.442 & 10.647 & 6.322 & 12.658 & 8.347 & 51.581 & 47.608 \\
Sheela & 49.238 & 46.88 & 9.965 & 6.352 & 11.649 & 9.947 & 51.579 & 48.351 \\
Shekhar & 50.247 & 45.343 & 10.127 & 6.032 & 11.949 & 8.711 & 52.634 & 46.566 \\
Sweta & 47.814 & 43.115 & 9.661 & 5.929 & 10.557 & 7.923 & 49.910 & 44.237 \\
Chambal & 47.364 & 45.585 & 9.009 & 5.678 & 10.650 & 8.275 & 49.377 & 46.677 \\
Suyog & 49.949 & 45.209 & 9.738 & 5.547 & 12.098 & 6.998 & 52.309 & 46.083 \\
Himani & 48.406 & 43.653 & 9.501 & 5.773 & 10.754 & 6.970 & 50.489 & 44.581 \\
Neelam & 48.470 & 46.604 & 9.500 & 5.957 & 10.930 & 8.276 & 50.589 & 47.707 \\
Surbhi & 63.916 & 51.262 & 10.738 & 10.244 & 24.772 & 16.005 & 69.385 & 54.674 \\
\hline
\end{tabular}

Sheela) to 761.59 (var. Shekhar) $\mathrm{kg} / \mathrm{m}^{3}$ and roasted linseed 459.14 (var. Sheela) to 801.32 (var. Neelam) $\mathrm{kg} / \mathrm{m}^{3}$. The porosity of the raw linseed ranged from $29.29 \%$ (var. Shekhar) to $47.99 \%$ (var. Sheela) and roasted linseed $8.15 \%$ (var. Neelam) to $43.73 \%$ (var. Sheela). The 1000-seed weight of raw linseed was in the range of 5.42 to $10.97 \mathrm{~g}$, where the least value was shown by Surbhi variety and highest value was recorded for Neelam variety of flaxseed and roasted linseed were in the range of 5.37 (var. Surbhi) to $10.47 \mathrm{~g}$ (var. Neelam). The $1000 \mathrm{seed}$ weight of linseed kernels were decreased after roasting as the removal of moisture from the kernel due to thermal treatment.

Frictional Properties: The static coefficient of friction was studied on four different surfaces ply perpendicular; ply parallel, galvanized iron and glass. It ranged from 0.32 to $0.39,0.30$ to 0.37 , 0.30 to 0.36 and 0.34 to 0.43 , respectively for raw linseed (Table 3). LC-2063 and LC-54 varieties shows least coefficient of friction on ply parallel and steel surface and variety Sweta shows highest coefficient friction on glass surface. Same as that roasted linseed varieties coefficient of friction studied on different four surfaces ply perpendicular, ply parallel, galvanized iron and glass. It ranged 0.34 to $0.43,0.32$ to $0.46,0.30$ to 0.34 and 0.27 to 0.34 , respectively (Table 3 ). Shekhar and LC-54 shows least coefficient of friction on glass and steel surface and Surbhi and Sheela shows highest coefficient of friction on ply parallel and ply perpendicular surface. The angle of repose of the studied raw linseed varieties ranged from $10.06^{\circ}$ to $24.45^{\circ}$ (Table 3). Raw linseed var. Surbhi shows least value and LC-54 shows highest value. Similarly roasted linseed variety ranged in $13.12^{\circ}$ (LC-54) to $20.68^{\circ}$ (Neelam).

Optical properties: The lowest and highest values for lightness "L" were found as 49.949 (Suyog) to 63.916 (Surbhi) (Table 4). L shows degree of lightness to darkness in which Surbhi variety shows highest value of lightness and Suyog shows lowest value respectively. Similarly, "a" shows degree of redness to greenness in which var. LC2063 (6.717) shows lowest value of redness and var. Surbhi (10.738) shows highest value of redness and degree of yellowness to greenness shows by "b" value in which var. sweta shows lowest value 10.557 and var. Surbhi shows highest value 24.772 in raw linseed. Comparatively after roasting of linseed change in value of "L", "a" and "b" observed. Var. Sweta (43.115) shows lowest value of lightness and var. Surbhi (51.262) shows highest value. LC-2063 (5.479) shows lowest value of redness and var. Surbhi (10.224) shows highest value of redness. Himani shows lowest value 6.970 and var. Surbhi shows highest value 16.005 of "b" in roasted linseed.

\section{Conclusion}

The variations found in the studied physical and optical properties on roasting of raw linseed may play a vital role for the development of storage, conveying, processing, handling and transportation equipments. Moreover, the optical properties may also be applied in order to maintain the quality of roasted linseed in an automated process based on the thermal treatments. 


\section{References}

1. Coskuner, Y. and Karababa, E. (2007). Some Physical Properties of Flaxseed (Linum Usitatissimum L.). J. Food Engg. 78:1073.

2. FAOSTAT (2013), http://www.faostat.org

3. Gupta, R. K. and Das, S. K. (2000). Fracture resistance of sunflower seed and kernel to compressive loading. J. Food Engg. 46: 1-8.

4. Jha, S. N. (1999). Physical and hygroscopic properties of makhana. J. Agric. Engg Res. 72: 145-150.

5. Konak, M., Carman, K. and Aydin, C. (2002). Physical properties of Chick Pea seeds. Biosys. Engg. 82: 73-78.

6. Oomah, B. D. (2001). Flaxseed as a functional food source. J. Sci. Food Agric.81: 889-894.

7. Prasad, K. (2003). Flaxseed and prevention of experimental hypercholesterolemic atherosclerosis. In Thompson, L. U. And Cunnane, S. C. Flaxseed in Human nutrition. $2^{\text {nd }}$ Edition, AOCS Press, Champaign, Illinois.
8. Prasad, K., Singh, Y. and Anil, A. (2012). Effects of grinding methods on the characteristics of Pusa 1121 rice flour, J. Trop. Agric. Food Sci. 40 (2): 193-201.

9. Prasad, K., Vairagar, P. R. and Bera, M. B. (2010). Temperature dependent hydration kinetics of Cicer arietinum splits. Food Res. Intern. 43 (2): 483-488.

10. Sharma, S. and Prasad K (2013) Comparative physical characteristics of Linseed (Linumusitatissimum) kernels. Intern. J. Agric.Food Sci. Technol. 4(7): 671-678.

11. Singh, K. K., Mridula, D., Barnwal, P. and Rehal, J. (2011). Selected Engineering and Biochemical Properties of 11 Flaxseed Varieties. Food Bioprocess Technol. DOI 10. 1007/S 11947-0110607-6.

12. Singh, Y. and Prasad, K. (2013). Physical characteristics of some of the paddy varieties as affected by shelling and milling, Oryza: An Intern. J. on Rice. 50: 174-180.

13. Thompson, L.U. (1995). Flaxseed in Human Nutrition. AOCS Press, Champaign. 219-236. 